\title{
FLORÍSTICA E FITOSSOCIOLOGIA DA COMUNIDADE INFESTANTE PRESENTE EM ÁREA DURANTE PROCESSO INICIAL DE RECUPERAÇÃO
}

\section{FLORISTIC AND PHYTOSOCIOLOGICAL ANALYSIS OF WEED COMMUNITY IN INITIAL RECOVERY OF NATIVE VEGETATION AREA}

\author{
Elisangela Ronconi Rodrigues
}

Faculdades Metropolitanas Unidas - FMU. E-mail: elisronconi@gmail.com

\begin{abstract}
RESUMO
Atualmente, muito tem se discutido sobre a importância de recuperação de áreas com vegetação nativa, visto o aumento crescente da destruição de ecossistemas em todas as regiões do Brasil. No tocante ao assunto, uma grande dificuldade dos pesquisadores está nos métodos disponíveis para o controle inicial de espécies exóticas invasoras, que competem com as essências nativas dificultando seu crescimento e desenvolvimento, sendo na maioria dos projetos a etapa mais onerosa e difícil de superar. Diante do exposto, este trabalho identificou as espécies invasoras presentes em uma área durante processo inicial de recuperação da vegetação nativa. Foram identificadas onze espécies distribuídas em sete famílias botânicas, as quais são comumente encontradas como plantas oportunistas em áreas cultivadas, mostrando a necessidade de maiores pesquisas para avaliar seus efeitos reais na competição com as espécies nativas em fase inicial de desenvolvimento.
\end{abstract}

Palavras-chave: Espécies exóticas invasoras. Restauração ecológica. Levantamento fitossociológico.

\begin{abstract}
Currently, much has been discussed about the importance of recovery of native vegetation areas, since the increasing destruction of ecosystems in all regions of Brazil. Regarding the subject, a great difficulty of researchers is in the methods available for the initial control of invasive exotic species that compete with native species hindering their growth and development, with most projects, the most costly and difficult to overcome stage. Given the above, this work has identified invasive species present in an area during the initial process of recovery of native vegetation. Eleven species distributed in seven plant families were identified, which are commonly found as opportunistic plants in cultivated areas, showing the need for further research to assess their actual effects on competition with native species in early stage of development.
\end{abstract}

Keywords: Invasive exotic species. Ecological restoration. Phytosociological analysis.

\section{1 - INTRODUÇÃO}

As primeiras iniciativas visando à recuperação de áreas degradadas são muito antigas no Brasil, e tiveram início no século XIX, quando 60 mil mudas de árvores foram plantadas por 
escravos numa área de 1600 hectares, que hoje constitui a Floresta da Tijuca, no Rio de Janeiro. Embora esta primeira ação de restauração ecológica no Brasil tenha sucedido ainda no século XIX, suas bases científicas foram introduzidas no país apenas na década de 1980. Por tratar-se de uma ciência recente e de caráter eminentemente multidisciplinar, seu escopo vem sendo delineado e redefinido constantemente (COSTA et al., 2005).

A recuperação de áreas degradadas não é um processo simples. Após sofrer um distúrbio, um sítio degradado perde, juntamente com a sua vegetação, os seus meios bióticos de regeneração, impedindo, assim, o retorno natural do ecossistema à sua condição inicial. Nesses casos, é necessária uma forte intervenção antrópica para que sejam superados impedimentos existentes à recuperação natural do ecossistema, possibilitando o retorno da área à condição pré-existente ou a algum estado estável permanente (RODRIGUES e GANDOLFI, 2001).

Atualmente, o controle de espécies invasoras em projetos de restauração ambiental é uma das etapas mais críticas e onerosas de todo o processo. Segundo Pitelli (2008), estima-se que 70\% do custo dos primeiros dois anos de implantação de matas ciliares são para o controle de plantas invasoras, que se refere àquelas espécies exóticas que ameaçam ecossistemas, habitats ou espécies, devido sua alta capacidade de crescimento, proliferação e dispersão, capazes de modificar a composição, estrutura ou função do ecossistema (ZILLER, 2000).

Espécies exóticas invasoras podem interferir na recuperação de áreas degradadas em diferentes aspectos. Primeiro, porque sua presença ou dominância em um sítio pode ser um importante indicador para avaliação do processo de recuperação. Segundo, as espécies exóticas podem ser as primeiras a colonizar um sítio após o processo de retirada da vegetação nativa, dificultando a condução do plantio nativo. Terceiro, porque mesmo após seu controle, estas espécies podem formar bancos de sementes que irão dificultar a gestão e manejo da área ao longo do processo de recuperação. (ANTONIO e MEYERSON, 2002).

Existem diversos trabalhos citando levantamentos fitossociológicos em áreas de cultura agrícola (BRIGHENTI et al., 2003; JAKELAITIS et al., 2003; SOUZA et al., 2003; ERASMO et al., 2004a; SILVA et al., 2006; KUVA et al., 2007). Nenhum levantamento, porém, para áreas em processo de recuperação florestal, o que torna importante conhecer quais espécies compõem a comunidade infestante da área e se estas realmente podem ser consideradas como plantas invasoras capazes de gerar prejuízos ao plantio florestal, devido a mato-competição com as mudas ou se são apenas espécies colonizadoras de solos descobertos, cujo ciclo de vida não interfere no desenvolvimento do plantio arbóreo.

De maneira geral, é importante considerar que o manejo de plantas invasoras em recuperação de áreas degradadas é uma nova linha de pesquisa em que se necessita uma série de dados de biologia e interferência destas plantas e as eficiências e impactos ambientais das várias modalidades de controle destas populações (PITELLI, 2008).

Diante do exposto, esta pesquisa teve como objetivo conhecer a comunidade infestante de um plantio de mudas florestais nativas em área degradada, analisando o potencial destas como espécies exóticas invasoras e capazes de gerar prejuízo ao desenvolvimento das mudas durante o início do processo de recuperação da área, momento em que estas são mais susceptíveis a matocompetição.

\section{2 - MATERIAL E MÉTODOS}

A área de estudo abrangida por esta pesquisa consiste em uma área de Reserva Legal, localizada no Assentamento Nova Esperança, Município de Euclides da Cunha Paulista, região do Pontal do Paranapanema, extremo oeste do Estado de São Paulo. O assentamento possui solos de baixa fertilidade natural e com alto grau de erodibilidade, agravado pelos anos de exploração de 
pastagens por parte dos antigos latifúndios, que por sua vez, davam pouca ou nenhuma importância para com o restabelecimento da fertilidade do solo ou mesmo por práticas de conservação (IPE, 2007).

A paisagem formada pelos 2.028 hectares do assentamento, no que se refere à presença de árvores é desoladora, encontradas somente nos 98 lotes de produtores oriundos da reforma agrária, tímidos quintais florestados. Existe um pequeno remanescente florestal bastante alterado, com 109,52 ha, que forma parte da Reserva Legal total do assentamento. O restante da área delimitada como Reserva Legal do assentamento encontra-se na forma de pastagens degradadas, portanto, deve ser recuperada (IPE, 2007). Assim, esta pesquisa se desenvolveu em uma área de 26,75 hectares de pastagem degradada em início de recuperação para recomposição da Reserva Legal do assentamento.

O método adotado para recuperação da área foi o plantio de mudas de espécies florestais nativas. O preparo do solo consistiu em duas gradagens, para mortalidade das gramíneas que compunham a pastagem e uma gradagem de nivelamento para o recebimento das mudas. $\mathrm{O}$ espaçamento adotado foi de $3 \times 2$ metros, num total de 1666 mudas por hectare. Foram instaladas na área 16 parcelas de $20 \times 30$ metros $\left(600 \mathrm{~m}^{2}\right.$ cada), distribuídas aleatoriamente, para amostragem da comunidade infestante nas entrelinhas do plantio de mudas.

A amostragem da comunidade infestante teve início seis meses após o plantio das mudas e ocorreu durante 18 meses de pesquisa, trimestralmente, totalizando 06 amostragens. O método adotado foi o do quadrado inventário (ERASMO et al., 2004a; ERASMO et al., 2004b), utilizandose um quadrado de $0,50 \mathrm{~m}^{2}$, lançado ao acaso oito vezes dentro das parcelas e contando-se o número de indivíduos dentro do quadrado.

As espécies invasoras ocorrentes nas amostragens foram coletadas para posterior identificação. A análise fitossociológica da comunidade infestante foi feita utilizando-se os parâmetros de Frequência Absoluta (FA), Densidade Absoluta (DA), Frequência Relativa (FR) e Densidade Relativa (DR). Tais parâmetros populacionais foram escolhidos devido às suas importâncias para o manejo das plantas daninhas, uma vez que o grau de interferência destas nas culturas depende não somente das espécies, mas de suas características de densidade e distribuição. (JAKELAITIS et al., 2003; SOUZA et al., 2003; VAZ DE MELO et al., 2007).

A espécie Brachiaria decumbens não foi considerada nesta pesquisa, visto que a área era uma pastagem abandonada e já possuía um banco de sementes desta espécie no solo. O objetivo da pesquisa foi amostrar as demais espécies que também atuam como plantas daninhas em projetos de recuperação de áreas degradadas.

\section{3 - RESULTADOS E DISCUSSÃO}

Durante os 18 meses de pesquisa, foram amostradas as espécies invasoras presentes em toda a área de estudo (TABELA 1). Os parâmetros fitossociológicos calculados para estas espécies encontram-se descritos na Tabela 2.

Foram identificadas onze espécies distribuídas em sete famílias botânicas, sendo que apenas Asteraceae e Malvaceae possuem mais de uma espécie representante. Esta baixa diversidade pode ser explicada pela predominância de Brachiaria decumbens, que por seus efeitos alelopáticos (VIDAL et al., 1986; STANIZIO et al., 1991; SOUZA FILHO et al, 1997; MARTINS et al., 2006; SOUZA et al. 2006), pode ter reduzido o banco de sementes do solo e gradativamente foi substituindo as demais espécies presentes. 
TABELA 1 - Espécies invasoras presentes na área de Reserva Legal em recuperação do Assentamento Nova Esperança, município de Euclides da Cunha Paulista - SP.

\begin{tabular}{|l|l|}
\hline FAMÍLIAS & ESPÉCIES \\
\hline Amaranthaceae & Amaranthus deflexus L \\
\hline Asteraceae & Chicorium intybus L \\
\hline & Gnaphalium pensylvanicum Willd. \\
\hline & Pterocaulon lanatum Kuntze \\
\hline Convolvulaceae & Dichondra microcalyx (Hallierf) Fabis \\
\hline Fabaceae & Sesbania exasperata Kunth \\
\hline Leg. Pap & Crotalaria lanceolata E. Mey. \\
\hline Malvaceae & Anoda cristata L. \\
\hline & Sida glaziovii K. Schum \\
\hline & Sida rhombifolia L. \\
\hline Solanaceae & Solanum viarum Dunal \\
\hline
\end{tabular}

TABELA 2 - Parâmetros fitossociológicos da comunidade infestante presente na área de Reserva Legal em recuperação do Assentamento Nova Esperança, município de Euclides da Cunha Paulista - SP, onde: FA = Frequência Absoluta; FR = Frequência Relativa; DA = Densidade Absoluta; DR = Densidade Relativa.

\begin{tabular}{|l|l|l|l|l|}
\hline ESPÉCIES & FA (\%) & FR (\%) & DA (plantas/m $\left.)^{2}\right)$ & DR (\%) \\
\hline Sida rhombifolia & 0,37 & 17,53 & 0,65 & 21,45 \\
\hline Sida glaziovii & 0,44 & 20,85 & 0,61 & 20,13 \\
\hline Chicorium intybus & 0,23 & 10,90 & 0,29 & 9,57 \\
\hline Pterocaulon lanatum & 0,14 & 6,63 & 0,26 & 8,58 \\
\hline Crotalaria lanceolata & 0,12 & 5,69 & 0,26 & 8,58 \\
\hline Gnaphalium pensylvanicum & 0,13 & 6,16 & 0,19 & 6,27 \\
\hline Dichondra microcalyx & 0,17 & 8,06 & 0,17 & 5,61 \\
\hline Sesbania exasperata & 0,16 & 7,58 & 0,17 & 5,61 \\
\hline Anoda cristata & 0,10 & 4,74 & 0,15 & 4,95 \\
\hline Solanum viarum & 0,15 & 7,11 & 0,16 & 5,28 \\
\hline Amaranthus deflexus & 0,10 & 4,74 & 0,12 & 3,96 \\
\hline
\end{tabular}


As espécies de Sida se destacaram em relação às demais na ocupação do solo, apresentando valores de frequência e densidade significantemente maiores quando comparadas as demais espécies. Juntas, as duas espécies somam uma densidade relativa de 41,58\%, mostrando seu predomínio na área. Ambas são citadas por Groth (1984), Mautone et al. (1990), Carvalho e Pitelli (1992) e Kill et al. (2000), como plantas invasoras.

Em terceiro lugar, observa-se a presença de Chicoruim intybus, planta de origem europeia e que no Brasil, conhecida popularmente como chicória, é cultivada para fins alimentícios e fitoterápicos (MENDES et al., 2005). A chicória é uma planta que cresce, espontaneamente, por toda a Europa e Ásia, em lugares secos, às margens dos caminhos e em terrenos baldios. Talvez por esse motivo, alguns autores a considerem, em alguns trabalhos científicos, a Chicorium intybus como uma espécie invasora (OLIVEIRA et al., 2004).

Também está presente neste levantamento outra planta cultivável, Crotalaria lanceolata, vulgarmente conhecida como guizo-de-cascavel, chocalho-de-cobra ou xiquexique. Originária da África foi introduzida no Brasil com a finalidade de cultivo de cobertura de solo e fornecimento de adubo verde (LORENZI, 2000), sendo considerada atualmente como uma planta invasora, em face de sua ampla disseminação (BACCHI et al., 1972).

A espécie Amaranthus deflexus é citada como espécie invasora de culturas agrícolas por Leitão-Filho (1968) e invasora de grande ocorrência no Brasil por Ferreira et al. (2003). Nesta pesquisa a espécie não apresenta valores expressivos de ocorrência, o que pode ser explicado por esses mesmos autores, que citam a espécie como típica de locais úmidos e férteis, condição não encontrada na área de reserva legal em recuperação.

Gnaphalium pensylvanicum é citada como espécie invasora em culturas de sorgo, aveiapreta e milho por Guglieri-Caporal (2011a). Figueiredo Neto et al. (2008), entretanto, citaram a ocorrência da espécie nas entrelinhas da cultura de café apenas como "planta daninha", que segundo a conceituação proposta pelos autores, são plantas não desejáveis, mas que não acarretam em prejuízo a cultura agrícola. Chapla e Campos (2011) amostraram a espécie como componente do banco de sementes durante processo sucessional em pastagem abandonada, ressaltando a ideia de que talvez esta não tenha comportamento invasor e seja apenas uma planta colonizadora de início de sucessão.

Ocorrente no Brasil, Pterocaulon lanatum apresenta ampla distribuição e é considerada como planta ruderal por Lorenzi (2000), o que pode ser fator para um comportamento invasor. Esta planta é citada por Biral e Lombardi (2012) como planta de ocorrência da flora de um remanescente de Floresta Estacional Semidecidual e por Guglieri-Caporal (2011b) como espécie de revegetação espontânea em voçoroca em uma pastagem, sendo que nenhum dos autores citam comportamento invasor da espécie.

Dichondra microcalyx é nativa do Brasil, herbácea, muito ramificada e que se espalha rapidamente na superfície plantada, devido sua propagação por rizomas, caracterizando sua agressividade enquanto invasora (Fischer et al., 2007). Considerada invasora também por Groth (1989) e por Oliveira (2011) e Maciel et al. (2010), como planta infestante em gramados de áreas ajardinadas.

Sesbania exasperata é citada por Chaves et al. (2012) como leguminosa indicada para cobertura inicial de solo em áreas degradadas por processos erosivos. Essas plantas podem ser utilizadas intencionalmente durante um processo de recuperação que envolva necessidades específicas, cujas espécies nativas não sejam capazes de suprir ou caso a degradação do sítio seja tão intensa que não favoreça o plantio de nativas (ANTONIO e MEYERSON, 2002).

Solanum viarum aparece na literatura como planta invasora ocorrente em culturas anuais, áreas de pastagens e áreas abandonadas, que se reproduz por sementes, as quais apresentam alto poder germinativo. (GROTH, 1989; MASCARENHAS et al., 2009; ROCHA et al., 2012). 
Anoda cristata é considerada como planta invasora de grande potencial expansivo em culturas de soja no Rio Grande do Sul por Ruedell e Zimmermann (1993). Santos et al. (2011), em estudo para avaliar a eficiência do uso de adubos verdes no controle de plantas infestantes da lavoura cafeeira, obtiveram resultados onde a população desta espécie não foi reduzida, mostrando grande potencial invasor.

Lima et al. (2009) citaram como importante e necessária à identificação das espécies da comunidade infestante, pois cada espécie apresenta o seu potencial de estabelecer-se na área e sua agressividade pode interferir de forma diferenciada em outras plantas. Para Fleck et al. (2008), o conhecimento das espécies e a utilização de práticas de manejo conjugadas contribuem para que o controle seja mais eficiente, pois espécies exóticas invasoras não apenas sobrevivem e se adaptam ao novo meio, mas também passam a exercer processos de dominância sobre a biodiversidade nativa. Essas alteram características naturais e o funcionamento de processos ecológicos, incorrendo em quebra de resiliência de ecossistemas naturais, redução de populações de espécies nativas e perda efetiva de biodiversidade.

Em função do grau de impacto registrado em todo o mundo, espécies exóticas invasoras constituem, atualmente, a segunda causa mundial de perda de diversidade biológica (ZILLER, 2000). Como agravante, as tecnologias para o controle de espécies invasoras não têm acompanhado o excessivo avanço da propagação destas, sendo as opções disponíveis poucas e muitas vezes ineficientes (SIGG, 1999).

Estudos em plantios comerciais e culturas agrícolas mostram que, para sobreviverem, os competidores disputam espaço físico, luz solar, nutrientes e água, sendo mais crítico o período inicial do plantio (PITELLI e MARCHI, 1991; TOLEDO et al., 2000). As interações competitivas entre espécies de plantas são afetadas por diversos fatores. Dentre os fatores ligados à comunidade infestante, a densidade de plantas é sem dúvida um dos fatores mais importantes, de tal forma que quanto maior for à densidade da comunidade infestante, maior será a quantidade de indivíduos que disputam os mesmos recursos do meio e, portanto, mais intensa será a competição sofrida pela cultura (CHISTOFFOLETI e VICTORIA FILHO, 1996). No presente estudo o levantamento não foi realizado em área de cultivo agrícola, entretanto, tais premissas podem ser assumidas para processos de mato-competição entre plantas invasoras e mudas de espécies arbóreas nativas em plantios de recuperação no início de seu desenvolvimento, justificando a necessidade do controle inicial, visto que estas podem formar grande quantidade de biomassa e exercer forte fator competitivo com mudas implantadas na área em recuperação.

\section{4 - CONCLUSÕES}

A presente pesquisa permitiu concluir que as espécies da comunidade infestante encontradas na área em processo de recuperação são comumente espécies oportunistas. Em diversos trabalhos na área agrícola, são citadas como invasoras capazes de gerar prejuízos as culturas, visto seu elevado potencial de crescimento e a agressividade de seu banco de sementes. A área de estudo por estar em processo de recuperação da vegetação nativa, quando ocorrem competições entre grupos vegetais fisiologicamente distintos, tornam-se necessárias mais pesquisas para avaliar a real influência das plantas invasoras no desenvolvimento das essências nativas. Isto se torna fundamental para se reduzir custos e catalisar a dinâmica de desenvolvimento das espécies arbóreas durante a fase inicial do projeto, momento mais crítico para o estabelecimento destas espécies. 


\section{5 - REFERÊNCIAS}

ANTONIO, C.D.; MEYERSON, L.A. Exotic Plant Species as Problems and Solutions in Ecological Restoration: A Synthesis. Restorarion Ecology, Washington D.C, v.10, n.4, p.703-713, 2002.

BACCHI, O.; LEITÃO-FILHO, H.F.; ARANHA, C. Plantas invasoras de culturas. São Paulo: HUCITEC, v.1, 1972. 291 p.

BIRAL, L.; LOMBARDI, J.A. Flora vascular da Mata da Pavuna, Botucatu, SP, Brasil. Revista Rodriguésia, Rio de Janeiro, v. 63, n.1, p.441-450, 2011.

BRIGHENTI, A.M.; CASTRO, C.; GAZZIERO, L.P.; ADEGAS, F.S.; VOLL, E. Cadastramento fitossociológico de plantas daninhas na cultura de girassol. Pesquisa Agropecuária. Brasileira, Brasília, v.38, n.5, p.651-657, 2003

CARVALHO, S.R.; PITELLI, R.A. Levantamento e análise fitossociológica das principais espécies de plantas daninhas de pastagens da região da Silvíria (MG). Revista Planta Daninha, Viçosa, v.10, n.1/2, p.25-32, 1992.

CHAPLA, T.E.; CAMPOS, J.B. Soil seed bank during succession at an abandoned pasture in the upper Paraná river-floodplain, Brazil. Acta Scientiarum Biological Science, Maringá, v.33, n.1, p.59-69, 2011.

CHAVES, T.A.; ANDRADE, A.G.; LIMA, J. A. S.; PORTOCARRERO, H. Recuperação de áreas degradadas por erosão no meio rural. Programa Rio Rural - Manual Técnico 34. Rio de Janeiro, 2012, 21 p.

CHRISTOFFOLETI, P.J.; VICTORIA FILHO, R. Efeitos da densidade e proporção de plantas de milho (Zea mays L.) e caruru (Amaranthus retroflexus L.) em competição. Planta Daninha, Viçosa, v.14, n.1, p.42-47, 1996.

COSTA, P.; ZILI, J.E.; TONINI, H.; XAUD, H.A.M. Recuperação de Áreas Degradadas e Restauração Ecológica de ecossistemas - Definições e Conceitos. Roraima: Embrapa Boa Vista, Documentos 07, 2005, 17 p.

ERASMO, E.A.L.; AZEVEDO, W.R.; SARMENTO, R.A.; CUNHA, A.M.; GARCIA, S.L.R. Potencial de espécies utilizadas como adubo verde no manejo integrado de plantas daninhas.

Revista Planta Daninha, Viçosa, v.3, n.2, p.337-342, 2004a.

ERASMO, E.A.L; PINHEIRO, L.L.A.; COSTA, N.V. Levantamento fitossociológico de plantas infestantes em áreas de produção de arroz irrigado cultivado sobre diferentes sistemas de manejo. Revista Planta Daninha, Viçosa, v.22, n.2, p.195-201, 2004b.

FERREIRA, E.A. Estudo anatômico de folhas de espécies de plantas daninhas de grande ocorrência no Brasil. IV - Amaranthus deflexus, Amaranthus spinosus, Alternanthera tenella e Euphorbia heterophylla. Revista Planta Daninha, Viçosa, v.21, n.2, p.263-271, 2003. 
FIGUEIREDO NETO, E.; ASCÊNCIO, F.; GERMINIANI, L.; PINOTI, E.B. Ocorrência de plantas daninhas no cafezal instalado no campus experimental coração da terra, Garça - SP. Revista Científica Eletrônica de Agronomia, Garça, n.14, 2008.

FISCHER, S.Z.; STUMPF, E.R.T.; HEIDEN, G.; BARBIERI, L R.; WASUN, R.A. Plantas da flora brasileira no mercado internacional de floricultura. Revista Brasileira de Biociências, Porto Alegre, v.5, supl.1, p.510-512, 2007.

FLECK, N.G.; LAZAROTO, C.A.; SCHAEDLER, C.E.; FERREIRA, F.B. Controle de papuã (Brachiaria plantaginea) em soja em função da dose e da época de aplicação do herbicida Clethodim. Planta Daninha, Viçosa, v.26, n.2, p.375-383, 2008.

GROTH, D. Caracterização morfológica das unidades de dispersão e das plântulas de cinco espécies invasoras da família Malvaceae. Revista Planta Daninha, Viçosa, v.7, n.2, p.53-71, 1984.

GROTH, D. Caracterização morfológica de sementes e plântulas de seis espécies invasoras do gênero Solanum L. Acta Botanica Brasilica, Belo Horizonte, v.3, n.1, p.25-47, 1989.

GUGLIERI-CAPORAL, A.; CAPORAL, F.J.M.; KUFNER, D.C.L.; ALVES, F.M. Flora invasora de cultivos de aveia-preta, milho e sorgo, em região de cerrado, Mato Grosso do Sul, Brasil.

Revista Bragantia, Campinas, v.70, n.2, p.247-254, 2011a.

GUGLIERI-CAPORAL, A.; CAPORAL, F.J.M.; POTT, A.; VINCI-CARLOS, H.C.; MORALES, C.A.S. Revegetação espontânea de voçoroca na região de cerrado, Mato Grosso do Sul, Brasil. Hoehnea, Campinas, v.38, n.2, p.289-306, 2011 b.

IPE - INSTITUTO DE PESQUISAS ECOLÓGICAS. Recuperação de Reserva Legal do Assentamento Nova Esperança. Relatório Técnico, 2007. 23 p.

JAKELAITIS, A.; FERREIRA, L.R.; SILVA, A.A.; AGNES, E.L.; MIRANDA, G.V.;

MACHADO, A.F.L. Dinâmica populacional de plantas daninhas sob diferentes sistemas de manejo nas culturas de milho e feijão. Planta Daninha. Viçosa, v.21, n.1, p.71-79, 2003.

KIILL, L.H.P.; HAJI, F.N.P.; LIMA, P.C.F. Visitantes florais de plantas invasoras de áreas com fruteiras irrigadas. Scientia Agricola. Piracicaba, v.57, n.3, p.575-580, 2000.

KUVA, M.A.; PITELLI, R.A.; SALGADO, T.P.; ALVES, P.L.C.A. Fitossociologia de comunidades de plantas daninhas em agroecossistema cana-crua. Planta Daninha. Viçosa, v.25, n.3, p.501-511, 2007.

LEITÃO FILHO, H.F. Espécies de Amaranthus que ocorrem como invasoras no município de Campinas. Boletim Científico do Instituto Agronômico do Estado de São Paulo, v.27, n.36, p.477 - 491,1968.

LIMA, J.M.; SILVA, C.A.; ROSA, M.B.; SANTOS, J.B; OLIVEIRA, T.G.; SILVA, M.B.

Prospecção fitoquímica de Sonchus oleraceuse sua toxidade sobre o microcrustáceo Artemia salina.

Planta Daninha, Viçosa - MG, v.27, n.1, p.207-11, 2009. 
LORENZI, H. Plantas daninhas do Brasil: terrestres, aquáticas, parasitas e tóxicas. Nova Odessa: Editora Plantarum, 2008. 640 p.

MACIEL , C.D.G.; SOUZA, J.I.; HAMA, J.T.. Levantamento fitossociológico de plantas daninhas em jardins residenciais com grama Esmeralda em Ourinhos - SP. Global Science and Technology. Rio Verde, v.3, n.2, p.39-48, 2010.

MARTINS, D. MARTINS, C.C., COSTA, N.V. Potencial alelopático de soluções de solo cultivado com Brachiaria brizantha: efeitos sobre a germinação de gramíneas forrageiras e plantas daninhas de pastagens. Planta daninha. Viçosa, v.24, n.1, p.61-70, 2006.

MASCARENHAS, M.H.T.; VIANA, M.C.M.; LARA, J.F.R.; BOTELHO, W.; FREIRE, F.M.; MACEDO, G.A.R. Flora infestante em pastagem degradada sob recuperação, pelo sistema de integração lavoura-pecuária, em região de cerrado. Revista Brasileira de Milho e Sorgo. Sete Lagoas, v.8, n.1, p.41-55, 2009.

MAUTONE, L.; BRANDÃO, M.; GUIMARÃES, E.F.; MIGUEL, J.R. Daninhas ocorrentes na zona serrana no estado do Rio de Janeiro, município de Petrópolis. Revista Acta Botanica Brasilica. Belo Horizonte, v.4, n.2, p.123-135, 1990.

MENDES, M.F.; CATALDO, F.R.; SILVA, C.A.; NOGUEIRA, R.I.; FREITAS, S.P. Extraction of the insuline from chicory roots (Chicorium intybus L.) using supercritical carbon dioxide. In: II Mercosur Congress on Chemical Engineering and IV Mercosur Congress on Process Systems Engineering. Rio de Janeiro, 2005. Anais. Rio de Janeiro: EMPROMER, 2005. 8 p.

OLIVEIRA, C.A.V.M. Fitossociologia da comunidade infestante de gramados de gramabatatais (Paspalum notatum FLÜGGE) em praças de Jaboticabal, SP. 2011, 58f. (Dissertação) Programa de pós-graduação em Agronomia - Produção Vegetal, UNESP, Jabuticabal, 2011.

OLIVEIRA, R.A.; PARK, K.J.; CHIORATO, M.; PARK, K.J.B.; NOGUEIRA, R.I. Otimização de extração de insulina de raízes de chicória. Revista Brasileira de Produtos Agroindustriais. Campina Grande, v.6, n.2, p.131-140, 2004.

PITELLI, R.A. Manejo de plantas daninhas em áreas ciliares: Aspectos técnicos e administrativos do processo de restauração florestal. In: II Simpósio de Atualização em Recuperação de Áreas Degradadas. Moji-Guaçu, 2008. Anais. São Paulo: IB, 2008, p.147-151.

PITELLI, R.A.; MARCHI, S.R. Interferência das plantas invasoras nas áreas de reflorestamento. In: III Seminário Técnico Sobre Plantas Daninhas e o Uso de Herbicidas Em Reflorestamento. Belo Horizonte, 1991. Anais. Belo Horizonte: SIF, 1991. p.1-11.

ROCHA, T.T.; GUIMARÃES, S.C.; SILVA, J.L.; DRESCH, E.C. Germinabilidade de sementes de Solanum viarum e Physalis angulata em função da exposição à luz. XXVIII Congresso Brasileiro da Ciência das Plantas Daninhas. Anais. Campo Grande, 2012, p.1-9.

RODRIGUES, R.R.; GANDOLFI, S. Conceitos, tendências e ações para a recuperação de florestas ciliares. In: RODRIGUES, R. R.; LEITÃO FILHO, H. Matas ciliares: conservação e recuperação. São Paulo: USP/Fapesp, 2001. p.235-247. 
RUEDELL, J.; ZIMMERMANN, T. Avaliação preliminar de herbicidas pós-emergentes no controle de Anoda cristata L. Schlecht na cultura de soja. XIV Reunião de Pesquisa de Soja na Região Sul. Anais. Chapecó - SC, 1986, p.51-55.

SANTOS, P.S.; MOURÃO, F.D.M.; CONCEIÇÃO, A.K.R.; SOUZA, G.V.; MARCHI, E. Efeito de adubos verdes na supressão de plantas espontâneas na lavoura cafeeira. $63^{a}$ Reunião Anual da SBPC, Anais. Goiânia - GO, 2011. Disponível em:

http://www.sbpcnet.org.br/livro/63ra/resumos/resumos/5120.htm

SIGG, J. The Role of herbicides in preserving biodiversity. California Exotic Plant Pest Council News, Summer/Fall 1999. (tradução). Disponível em:

http://www.institutohorus.org.br/download/artigos/papelherb.pdf (Consulta em 10/03/2010).

SILVA, S.O.; MATSUMOTO, S.N.; BEBÉ, F.V.; SÃO JOSÉ, A.R. Diversidade e frequência de plantas daninhas em associações entre cafeeiros e grevíleas. Coffee Science. Lavras, v.1, n.2, p.126-134, 2006.

SOUZA, L.S.A.; SILVA, J.F.; SOUZA, M.D.B. Composição florística de plantas daninhas em agroecossistemas de cupuaçuzeiro (Theobroma grandiflorum) e pupunheira (Bactris gasipaes).

Planta Daninha. Viçosa - MG, v.21, n.2, p.249-255, 2003

SOUZA, L.S.; VELINI, E.D.; MARTINS, D.; ROSOLEM, C.A. Efeito alelopático de capimbraquiária (Brachiaria decumbens) sobre o crescimento inicial de sete plantas cultivadas. Planta Daninha. Viçosa - MG, v.24, n.4, p.657-688, 2006.

SOUZA FILHO, A.P.S.; RODRIGUES, L.R.A.; RODRIGUES, T.J.D. Potencial alelopático de forrageiras tropicais: efeitos sobre invasoras de pastagens. Planta Daninha. Viçosa - MG, v.15, n.1, p.53-60, 1997.

TOLEDO, R.E.B.; VICTÓRIA FILHO, R.; PITELLI, R.A.; ALVES, P.L.C.A.; LOPES, M.A.F.V. Efeitos de períodos de controle do capim-braquiária (Brachiaria decumbens) no desenvolvimento inicial de plantas de eucalipto. Planta daninha, Viçosa - MG, v.18, n.3, p.383-393, 2000.

VAZ DE MELO, A.; GALVÃO, J.C.C.; FERREIRA, L.R.; MIRANDA, G.V.; TUFFI SANTOS, L.D.; SANTOS, I.C.; SOUZA, L.. Dinâmica Populacional de plantas daninhas em cultivo de milho verde nos sistemas orgânico e tradicional. Planta Daninha,Viçosa - MG, v.25, n.3, p.521-527, 2007

ZILLER, S.R.A. Estepe Gramíneo-Lenhosa no Segundo Planalto do Paraná: Diagnóstico Ambiental Com Enfoque à Contaminação Biológica. 2000, 277f. (Tese). Programa de pósgraduação em Engenharia Florestal, Universidade Federal do Paraná. Curitiba, 2000. 